\title{
RESEARCH
}

Open Access

\section{Identifying and predicting food parenting practice profiles among Canadian parents}

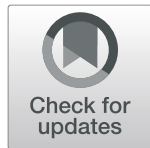

Claire N. Tugault-Lafleur ${ }^{1}$, Olivia De-Jongh González², Teresia M. O'Connor ${ }^{3}$, Sheryl O. Hughes ${ }^{3}$ and Louise C. Mâsse $2^{2^{*}}$ (i)

\begin{abstract}
Background: Food parenting practices (FPP) can affect children's eating behaviours, yet little is known about how various FPP co-occur. The primary aim was to identify profiles of FPPs use among Canadian parents. Secondary aims included examining sociodemographic correlates of FPP profiles and evaluating whether children's eating behaviours differed across FPP profiles.

Methods: Parents $(n=799)$ of 5 -12-year-old children completed a validated FPP Item Bank and the Children's Eating Behaviour Questionnaire. Latent Class Analysis (LCA) was used to identify distinct FPP profiles. Regression analyses were used to explore associations between FPP profiles, sociodemographic variables (race, sex and education) and children's eating behaviours (emotional overeating, food responsiveness, food fussiness and satiety responsiveness).
\end{abstract}

Results: LCA revealed 6 FPP profiles: healthy eating environment, high engagement, reactive, high structure, controlling and low engagement. Relative to their non-White counterparts, White parents were more likely to belong in the healthy eating environment, high structure and low engagement profiles. Relative to fathers, mothers were more likely to fall in the healthy eating environment compared to low engagement profile. Parents with some postsecondary education were more likely to belong in the healthy eating environment, high structure and reactive profiles compared to the controlling profile. Emotional overeating and food responsiveness scores were lowest for healthy eating environment, high structure, low engagement profiles. Parents in the healthy eating environment profile also reported lower food fussiness scores compared to parents in the high engagement, high structure, reactive and controlling profiles.

Conclusions: Findings suggest that a continuum of 6 FPP profiles may be present among Canadian parents, representing parents who use either all (high engagement), some (healthy eating environment, reactive, high structure, controlling) or little (low engagement) of the FPP examined. Future longitudinal research should evaluate how various FPP profiles influence the development of children's eating behaviors, dietary intakes and weight status.

Keywords: Food parenting practices, Eating behaviours, Children, Latent class analysis

\footnotetext{
* Correspondence: Imasse@bcchr.ubc.ca

${ }^{2}$ School of Population and Public Health University of British Columbia, BC Children's Hospital Research Institute, F508-4490 Oak Street, Vancouver, BC V5Z 4H4, Canada

Full list of author information is available at the end of the article
}

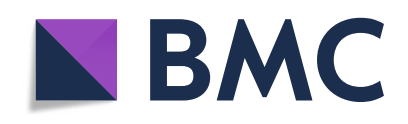

(- The Author(s). 2021 Open Access This article is licensed under a Creative Commons Attribution 4.0 International License, which permits use, sharing, adaptation, distribution and reproduction in any medium or format, as long as you give appropriate credit to the original author(s) and the source, provide a link to the Creative Commons licence, and indicate if changes were made. The images or other third party material in this article are included in the article's Creative Commons licence, unless indicated otherwise in a credit line to the material. If material is not included in the article's Creative Commons licence and your intended use is not permitted by statutory regulation or exceeds the permitted use, you will need to obtain permission directly from the copyright holder. To view a copy of this licence, visit http://creativecommons.org/licenses/by/4.0/. The Creative Commons Public Domain Dedication waiver (http://creativecommons.org/publicdomain/zero/1.0/) applies to the data made available in this article, unless otherwise stated in a credit line to the data. 


\section{Introduction}

Children's eating behaviors are influenced by a multitude of factors interacting at multiple levels including the community, household/family and child-level $[1,2]$. Within the home environment, food parenting practices (FPP) (strategies and behaviours parents use to influence children's nutrition-related behaviours and outcomes [3]) can play an integral role in children's eating habits and weight status [4]. Vaughn and colleagues have proposed a content map presenting 3 overarching food parenting constructs (coercive control, structure and autonomy promotion) as well as specific practice subconstructs [3]. The coercive control domain includes strategies such as pressure to eat, restriction, using food as reward (or as a way to control negative emotions), all of which have been linked with emotional overeating in children $[5,6]$. The structure domain includes noncoercive forms of FPP such as guided choice, routines and rules, modeling, vegetables and fruit availability and accessibility to help children maintain health-promoting behaviours [3]. Finally, the autonomy support domain is exemplified by FPP such as nutrition education, child involvement, encouragement, praise, reasoning and negotiation [3].

Examining how single FPP influence children's eating behaviours is problematic because it ignores the cooccurrence of various FPP with one another (parents draw on a wide range of FPP which may cluster with one another [3, 7]). FPPs can also be fluid (parents may use various FPPs apparently in conflict with one another depending on a specific situation or context [8]). Within the parenting literature which recognizes that parents use multiple FPP [3, 7-10], there has been calls to use more person-centered approaches to data analysis (assigning parents to food parenting 'profiles' based on multiple dimensions) rather than a variable-centered approach (that ignores the interrelationships between measures) [11].

To date, limited research has examined the cooccurrence of FPP and which profile of FPP influence children's eating behaviours. Drawing on a relatively small sample of parents $(n=150)$ with young children (5-7 years), Jennings et al. [12] identified 2 groups of parents based on varied combinations of parenting styles and practices using latent profile analysis. Parents in group 1 were more likely to use both authoritarian and permissive parenting styles in combination with coercive controlling FPP, whereas parents in group 2 reported using a more authoritative parenting style. Parents in the first group reported having children who were more food responsive and lacked internal cues for satiety compared to parents in the second group. Drawing from a larger representative sample of U.S. parent-adolescent dyads $(n=1657)$, Thomson et al. [13] identified a continuum of 5 latent classes (parent-adolescent groups) based on the use of FPP related to fruit and vegetables and found that both demographic (child age, sex) and dietary characteristics (fruit and vegetable intakes) were associated with latent class membership.

Knowledge on what clusters of FPP are used and which of these impact children's eating behaviours can help guide clinicians design effective, person-centered interventions to guide parents towards health promoting FPPs. Therefore, the purpose of this study was to identify profiles of parents based on their use of various FPP. Secondary aims included examining sociodemographic factors associated with parent profiles and evaluating whether children's eating behaviours differed across parent profiles.

\section{Methods}

\section{Participants}

This cross-sectional study drew from a sample of 799 parents of 5-12 years old children. This web-based panel of participants were recruited by Insight West, a marketing research company in British Columbia, Canada. The sampling procedure used a quota sampling approach by sex, income (using the 2015 median income of Canadian parents), and race or ethnicity (White, Asian, South Asian, and others) to ensure a diverse representation of Canadian parents. The research protocol was approved by the Research Ethics Board of the University of British Columbia, and participants provided their signed informed consent.

\section{Measures \\ Food parenting practices}

Parents completed the online FPP Item Bank, which drew on an expert-informed conceptual framework assessing three key domains of FPP (autonomy promotion, control, and structure) and associated food parenting practices [14]. The psychometric properties of the Food Parenting Practices Item Bank has been previously validated using advanced psychometric methods [15]. Definitions and descriptive statistics for each of the 11 constructs measured in the item bank are provided in Table 1. A 1-5 response scale was used to measure each construct. Respondents' answers were all recoded so that a higher score suggests a higher endorsement ("strongly disagree"- "strongly agree") or higher frequency of use (from "never" to "often" or from "never" to "5 to 7 times per week") for each construct. Constructs were dichotomized above and below the median of the original 5point response format, where a higher score indicated more agreement or frequency in the use of a food parenting practice. We used the median to dichotomize each indicator variable in order to control for the social desirability bias inherent to self-reporting and to account 


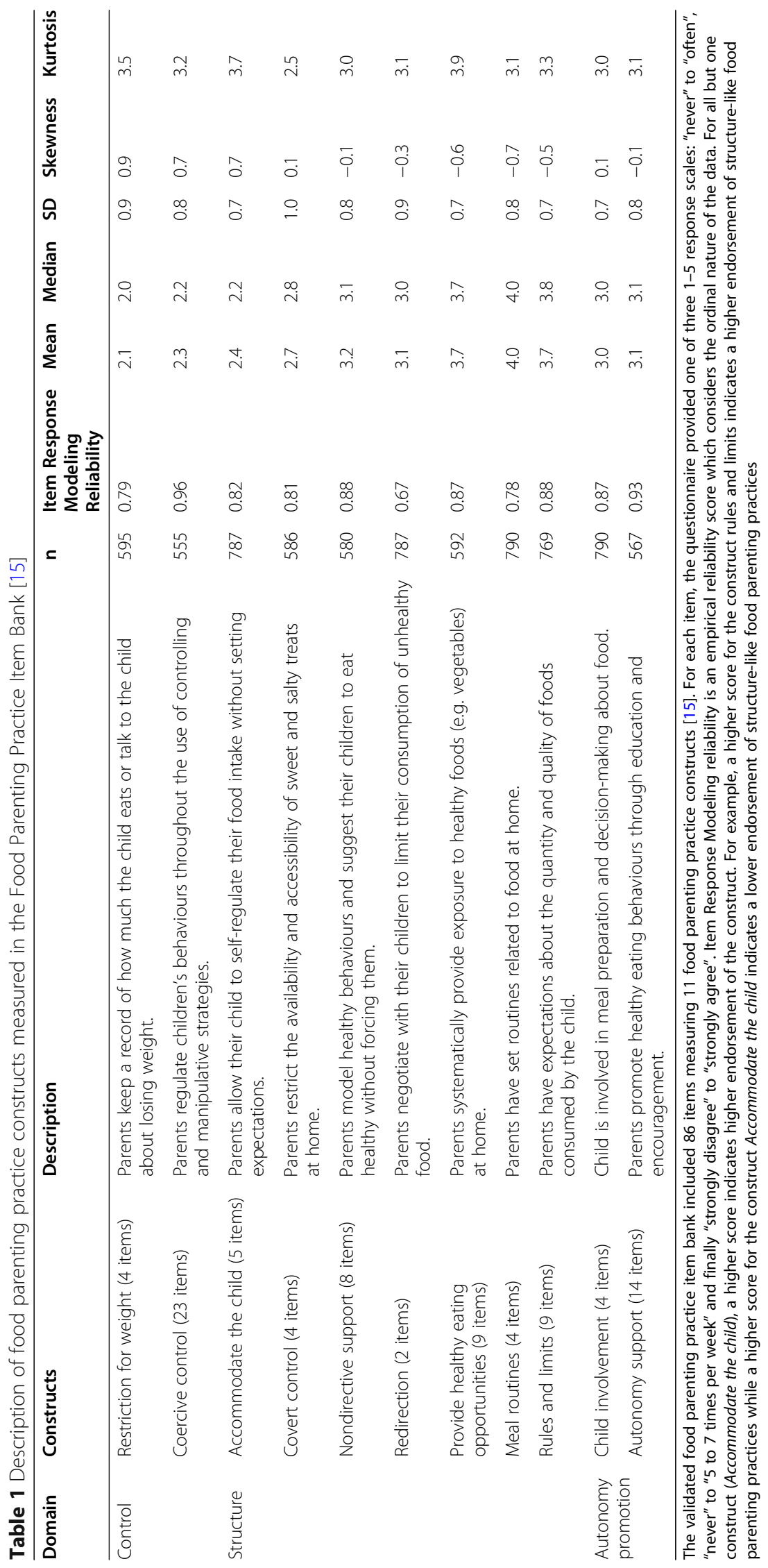


for the ceiling or flooring effect with some of the constructs (see Table 1).

\section{Children's eating behaviours}

The Children's Eating Behaviours Questionnaire [16] is a validated questionnaire designed to assess children's appetite using 8 factors which have been divided into two 2 dimensions: food approach and food avoidance [17]. In this study, we used a reduced version of the questionnaire (20 items) to measure 4 specific behaviours: emotional overeating (4 items measuring whether the child eats more in presence of negative emotions), food responsiveness (5 items measuring whether the child wants to eat for pleasure in the absence of hunger cues), food fussiness (6 items measuring whether the child is selective with foods) and satiety responsiveness (5 items measuring whether the child gets full before his/her meal is finished). These eating behaviours were chosen as they reflect individual differences in eating selfregulation and have been linked with child weight status in previous research [18]. While emotional overeating and food responsiveness have been described as falling within the "food approach" dimension and refer to a movement towards or desire for food, food fussiness and satiety responsiveness fall within the "food avoidant" dimension and involve movement away from food [17]. These constructs were measured using a 1-5 response scale assessing the frequency of the behaviour (from "never" to "always") in which the higher the score, the more frequent the behaviour. Constructs' Cronbach's $\alpha$ for the Children's Eating Behaviour Questionnaire range from 0.72 to 0.91 [16].

\section{Socio-demographic variables}

Other variables of interest included parental sociodemographic characteristics. Demographic data included parental age, sex, marital status and race/ethnicity. The original race/ethnicity variable was adapted from the Canadian population-based surveys and posed to parents as follows: "People living in Canada come from different cultural and racial backgrounds. What is your racial or ethnic background?" with 8 possible response options: White/European, Aboriginal (e.g. North American Indian, Metis, Inuit, etc.), Chinese, South Asian (e.g. East Indian, Pakistani, Sri Lankan, etc.), Black, South East Asian (e.g. Vietnamese, Malaysian, Filipino, etc.), Japanese, Other (specify). To describe our parent sample (Table 2), we used a recoded race/ethnicity variable classifying parents as White/European vs. non-White, Asian (Chinese, Southeast Asian, or Japanese), South Asian (East Indian, Pakistani, Sri Lankan), and Other (Other, Aboriginal or Black). For objective 2 (correlates of profile membership), we dichotomized the recoded race/ ethnicity variable into White vs. non-White due to the small number of participants within each of the nonWhite racial groups. Socio-economic data included total household income and parental educational attainment. The original parental education variable included 7 potential response options: some high school, high school degree or GED, some college or university, college or non-university certificate, Bachelor's degree, university degree above the Bachelor's level, or professional degree (e.g. MD, DDS, JD). To facilitate comparison with previous studies $[19,20]$, the educational attainment variable was dichotomised into "no post-secondary education" (i.e. high school degree or GED or below) vs. "some post-secondary education".

\section{Statistical approach}

LCA is a statistical technique that identifies categorical latent class variables based on observed indicator variables [21]. In the context of this study, Latent Class Analysis (LCA) was used to identify latent 'classes' or profiles based on their use of 11 FPP. The robust maximum likelihood estimator with the expectationmaximization algorithm was used with 1000 random starts. Recommendations from Nylund-Gibson \& Young [22] and Bray et al. [23] were followed when selecting the number of classes. Models from 1 up to 7 classes were explored and different fit indexes and information criteria were computed: Bayesian Information Criterion (BIC); Sample-size Adjusted Bayesian Information Criterion (SABIC); Akaike information criterion (AIC); consistent Akaike information criterion (CAIC); and approximate weight of evidence criterion (AWE). Relative indices comparing neighboring model of classes were also evaluated. For Vuong-Lo-Mendell-Rubin likelihood ratio test (VLMR-LRT) and bootstrap likelihood ratio test (BLRT), a significant $p$-value in one model ( $\mathrm{k}$ classes) means that such model is better than the previous one ( $k-1$ classes). For bayes factor (BF), the higher the score, the stronger the evidence for $k$ class model over the $\mathrm{k}+1$ class model. Third, correct model probability $(\mathrm{cmP})$ was used to estimate how each model is corrected by all models considered (assuming that the correct one is among them), and higher values are desirable. Finally, relative sample sizes, interpretability and utility of the obtained classes were considered when deciding on the final number of classes. After the $\mathrm{k}$ class model was selected, other criteria such as entropy and average posterior probability (avePP) were considered. An entropy value above 0.8 represents a good classification of the participants into the classes, whereas the avePP $>70 \%$ represents well-differentiated classes. While the term 'class' is standardised terminology used when describing profiles based on observed indicator variables [24], we use the term 'profile' in the remainder of this study to avoiding confusion with the term 'social class'. 
Multinomial logistic regression models were used to evaluate whether sociodemographic variables (parental sex, race/ethnicity, and education) were significant predictors of parent profiles. To examine associations between children's eating behaviours and FPP profiles, multivariable linear regression models examined differences in eating behaviour scores across latent classes while controlling for parental sex, race, educational attainment as well as children's age and sex. Missing data were handled using case-wise deletion. Significance level was set at $p<0.01$ to account for the multiple comparisons and maintain an adequate balance between statistical power and rate of Type I error. The LCA analyses were conducted with the Mplus software version 8.4 [25]. All other analyses were conducted in Stata version 16 [26].

\section{Results}

Table 2 shows the sociodemographic characteristics of study participants. The sample was evenly distributed between mothers and fathers of 5-12-year-old children and the majority (86\%) of parents were married. Just over half of participants (51\%) self-identified as White. Twenty-two percent of parents self-identified as East Asian (Chinese, Japanese and Southeast Asians) and 16\% self-identified as South Asian (East Indian, Pakistani, Sri Lankan, etc.). The remainder of the sample (11\%) selfidentified as either Black, Aboriginal/Metis or 'other'

Table 2 Characteristics of participants in the Food Parenting Study

\begin{tabular}{|c|c|}
\hline Characteristics & $\% /$ mean $\pm S D$ \\
\hline Parent age & $33.1 \pm 8.5$ \\
\hline Sex, \% female & $50 \%$ \\
\hline Marital status, \% married & $86 \%$ \\
\hline \multicolumn{2}{|l|}{ Race/ethnicity } \\
\hline White & $51 \%$ \\
\hline East Asian (Chinese, Japanese, Southeast Asian, etc.) & $22 \%$ \\
\hline South Asian (East Indian, Pakistani, Sri Lankan, etc.) & $16 \%$ \\
\hline Black, Aboriginal, or 'other' & $11 \%$ \\
\hline \multicolumn{2}{|l|}{ Parental education ${ }^{a}$} \\
\hline No post-secondary education & $13 \%$ \\
\hline Post-secondary education & $87 \%$ \\
\hline \multicolumn{2}{|l|}{ Household income (\$CAN) } \\
\hline Less than $\$ 50,000$ & $22 \%$ \\
\hline$\$ 50,000$ to $\$ 99,999$ & $51 \%$ \\
\hline$\$ 100,000$ to $\$ 149,999$ & $18 \%$ \\
\hline$\$ 150,000$ or higher & $93 \%$ \\
\hline Children's age & $9.1 \pm 2.4$ \\
\hline
\end{tabular}

SD standard deviation. $\mathrm{N}=799$ parents of children aged 5-12 years ${ }^{a}$ Missing data on $n=199$ respondents. All other variables have complete (non-missing) data racial group. Most parents (86\%) had obtained some post-secondary education and $22 \%$ of the sample had an annual household income lower than CAN\$50,000.

\section{Profiles of food parenting practices}

Using the dichotomized food parenting constructs, we fitted a series of LCA models beginning with a 1-profile model and stopping with a 7-profile model. Fit indices for these 7 models are shown in Table 3 . All fit indices did not converge over a single solution and this is generally the rule rather than the exception [22]. As shown in Table 3, many of the fit indices improved with more profiles and many of the fit indices suggested that a 7profile solution might be the best fit (SABIC, AIC, CAIC, and BF). However, for some of these indices, the improvement was minimal (CAIC) and some indices (entropy) deteriorated after 5 profiles, BIC (optimal with the 5-profile model), VLMR-LRTp (optimal with the 3or 5-profile model) and $\mathrm{cmP}$ (optimal with the 4-profile model). In light of the variability in the fit indices, the interpretability of the solutions from a 3- to 7-profile model was evaluated. A 6- profile solution was retained as it was deemed to yield interpretable profiles based on the 11 FPP constructs.

Figure 1 shows the 6 parent profiles based on their probability of "low" or "high" endorsement of 11 FPP constructs. The first profile (9\% of parents) was labelled healthy eating environment because parents in this profile showed a high endorsement towards providing healthy eating opportunities and involving their child into meal preparation and decision-making around food. The second profile labelled high engagement $(17 \%$ of parents) included parents who showed high endorsement for almost all FPP. Parents in the high engagement group showed particularly high probabilities of endorsing FPP related to control and structure as well as autonomy promotion. The third profile was labelled high structure (25\% of parents) because respondents showed high endorsement for FPP falling within the structure domain (i.e. parents tend to have a low endorsement for accommodating the child along with a high endorsement of routines and rules). High structure parents also reported low use of controlling FPP and lacked autonomy promoting FPPs. The fourth profile, representing $17 \%$ of the sample, was labelled reactive because parents in this profile showed high endorsement for controlling and autonomy promoting FPP along with a low endorsement of structure-like FPPs such as routines and rules. The fifth profile ( $16 \%$ of parents) was labelled controlling because parents showed only high endorsement of controlling FPP along with low endorsement of structure and autonomy promoting FPP. Finally, the last and sixth profile (15\% of parents) was labelled low engagement 
Table 3 Model fit statistics for latent profile analyses

\begin{tabular}{|c|c|c|c|c|c|c|c|c|c|c|c|}
\hline $\bar{K}$ & LL & BIC & SABIC & AIC & CAIC & AWE & VLMR-LRTp & BLRTp & $\mathrm{BF}$ & $\mathrm{cmP}$ & Entropy \\
\hline 1 & -5095.77 & $10,265.06$ & $10,230.13$ & $10,213.54$ & $10,234.47$ & $10,239.97$ & - & - & 0.00 & 0.00 & - \\
\hline 2 & -4812.03 & 9777.77 & 9704.74 & 9670.06 & 9713.81 & 9725.31 & 0.314 & $<0.001$ & 0.00 & 0.00 & 0.621 \\
\hline 3 & -4626.77 & 9487.46 & 9376.31 & 9323.54 & 9390.13 & 9407.63 & 0.005 & $<0.001$ & 0.11 & 0.04 & 0.713 \\
\hline 4 & -4564.90 & 9443.91 & 9294.66 & 9223.79 & 9313.21 & 9336.71 & 0.409 & $<0.001$ & 1.24 & 0.39 & 0.683 \\
\hline 5 & -4526.95 & 9448.22 & 9260.87 & 9171.90 & 9284.15 & 9313.65 & 0.029 & $<0.001$ & 1.49 & 0.31 & 0.737 \\
\hline 6 & -4490.83 & 9456.18 & 9230.71 & 9123.66 & 9258.74 & 9294.24 & 0.353 & $<0.001$ & 4.50 & 0.21 & 0.721 \\
\hline 7 & -4465.76 & 9486.25 & 9222.68 & 9097.53 & 9255.44 & 9296.94 & 0.096 & $<0.001$ & 8.44 & 0.05 & 0.709 \\
\hline
\end{tabular}

$K$ number of profiles, LL log-likelihood, BIC Bayesian information criterion, SABIC sample-size adjusted BIC, AIC Akaike information criterion, CAIC consistent AIC, $A W E$ approximate weight of evidence criterion, $p$ error probability, VLMR-LRT Vuong-Lo-Mendell-Rubin adjusted likelihood ratio test, BLRT bootstrapped likelihood ration test, $B F$ Bayes factor, $C M P$ correct model probability. Bolded values indicate best fit for each respective statistic

parents because these FPP users showed low endorsement for all $11 \mathrm{FPP}$.

\section{Predictors of latent FPP profiles}

Figure 2 shows the sex, racial and educational attainment distribution of parents within each of the 6 parent profiles (Supplemental Table 1 shows the exact proportion or percent (\%) of demographic characteristics within each parent profile). Mothers were more likely to belong to the healthy eating environment profile compared to the low engagement profile whereas a higher proportion of fathers fell in the low engagement profile compared to the healthy environment profile. Relative to their non-White counterparts, White parents were more likely to belong in the healthy eating environment, high structure and low engagement profiles compared to the high engagement, reactive and controlling profiles. Relative to parents with no post-secondary education, parents with some post-secondary education were more likely to belong in the healthy eating environment, high structure and reactive profiles compared to the controlling profile.

\section{Children's eating behaviours across latent profiles}

Children's mean scores for the 4 eating behaviours examined (emotional overeating, food responsiveness, food

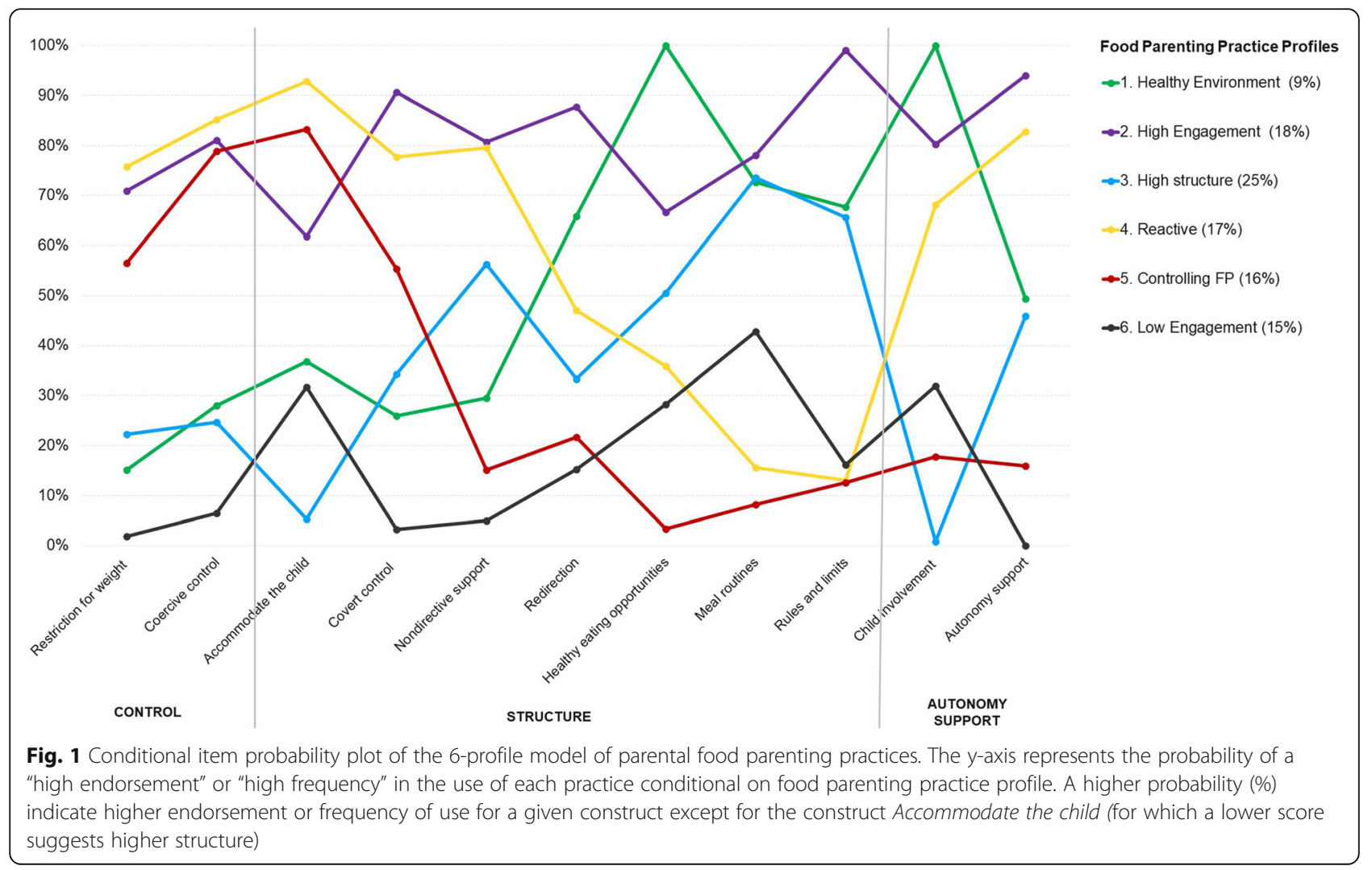




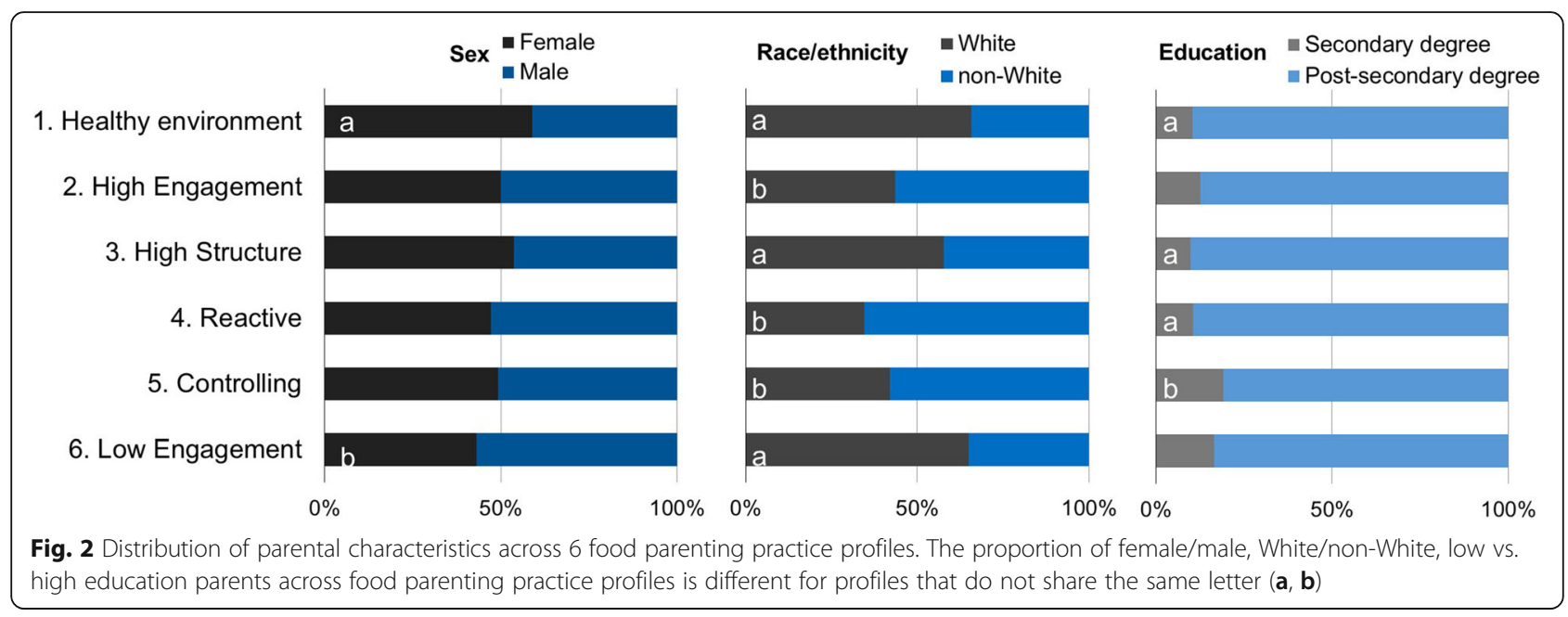

fussiness and satiety responsiveness) across the six parent profiles are shown in Table 4. Parents in the high engagement, reactive and controlling profiles reported significantly higher scores for emotional overeating and food responsiveness compared to parents in the healthy eating environment, high structure and low engagement profiles. Parents in the high engagement, high structure, reactive and controlling profiles also reported higher food fussiness scores compared to parents in the healthy eating environment profile. Finally, parents falling in the high engagement and reactive profiles reported significantly higher satiety responsiveness scores compared to parents in the healthy eating environment and low engagement profiles. Parents in the reactive profile also reported higher satiety responsiveness scores compared to parents in the high structure profile.

\section{Discussion}

The present study used data from a diverse sample of Canadian parents to identify distinct profiles of parents based on their uses of 11 FPP constructs. LCA revealed six FPP profiles ranging from very little use to parents who reported using almost all FPP examined (along with various combinations of controlling, structure and autonomy promoting FPP).

Based on evidence examining the influence of individual FPP on children's nutritional outcomes [3], we ranked each profile from the most favorable to the least favorable profile in the following order: healthy eating environment, high engagement, reactive, high structure, controlling, and low engagement profiles. Parents falling in the healthy eating environment profile (the smallest profile including only $9 \%$ of the sample) showed high endorsement of structure and autonomy promoting FPP and contrasted with the controlling profile who reported using only controlling FPP. The high structure profile (the largest profile including $25 \%$ of the sample) included parents who showed little endorsement of controlling and autonomy promoting FPP but showed high endorsement of routines and rules. In contrast, parents in the reactive profile showed high endorsement of controlling and autonomy promoting FPP but lacked any

Table 4 Average children's eating behaviour scores across 6 food parenting practice user profiles

\begin{tabular}{lllll}
\hline \multirow{2}{*}{ Latent profiles } & \multicolumn{3}{l}{ Children's eating behaviour scores } \\
\cline { 2 - 5 } & Emotional overeating & Food responsiveness & Food fussiness & Satiety responsiveness \\
\hline 1. Healthy eating environment & $1.72 \pm 0.10$ & $2.25 \pm 0.09$ & $2.36 \pm 0.09$ & $2.67 \pm 0.08$ \\
2. High engagement & $2.52 \pm 0.08$ & $2.91 \pm 0.08$ & $2.79 \pm 0.07$ & $3.01 \pm 0.06$ \\
3. High structure & $1.70 \pm 0.07$ & $2.28 \pm 0.06$ & $2.71 \pm 0.06$ & $2.78 \pm 0.05$ \\
4. Reactive & $2.57 \pm 0.08$ & $2.97 \pm 0.07$ & $2.87 \pm 0.07$ & $3.11 \pm 0.06$ \\
5. Controlling & $2.44 \pm 0.09$ & $2.69 \pm 0.08$ & $2.97 \pm 0.07$ & $2.91 \pm 0.06$ \\
6. Low engagement & $1.60 \pm 0.09$ & $2.19 \pm 0.08$ & $2.68 \pm 0.07$ & $2.69 \pm 0.06$ \\
Latent profile differences $^{a}$ & $1,3,6$ vs $2,4,5$ & $1,3,6$ vs. 2, 4, 5 & 1 vs. 2, 3, 4, 5 & 1,6 vs. 2, 4 \\
\end{tabular}

Behaviour scores can vary from 0 to 5 points where the higher the score, the more frequent the behaviour

${ }^{a}$ Multivariable linear regression models examined differences in CEBQ scores (emotional overeating, food fussiness, food responsiveness and satiety responsiveness) across the six profiles. Covariates included parental sex, race/ethnicity, educational attainment as well as children's age and sex. Significance level was set at 0.01 , to account for the multiple comparisons and maintain an adequate balance between statistical power and Type I error rate 
structure. The latter profile could group parents who use two practices that are apparently in conflict with one another.

Few studies have used LCA to identify FPP profiles among parents. In a sample of ethnically diverse, low income U.S. parents, Jennings and colleagues [12] used latent profile analysis and identified two parent profiles based on both their parenting styles and FPP. Parents in the first profile included parents who used both authoritarian and permissive parenting styles along with controlling FPP (e.g. restriction, pressure to eat) (overall, a less favorable profile) whereas parents in the second profile used more an authoritative parenting style along with less controlling FPP (overall, a more favorable pattern). In contrast to Jennings et al.'s study, our study did not include parenting styles and drew on a larger sample of parents with older children. We also included a wider range of FPP as indicator variables. Our findings suggest a continuum of 6 FPP profiles may be present, representing parents who use either all (high engagement), some (healthy eating environment, reactive, high structure, controlling) or little (low engagement) of the FPPs examined. In another U.S. study conducted among parent-adolescent dyads, Thompson et al. identified 5 parent profiles based on parental use of pressure to eat, monitoring, modeling, encouragement, availability and child involvement regarding their child's fruit and vegetable intake. Two of the FPP profiles were somewhat analogous to our study. The indifferent influencers profile reported low use of all FPPs similar to the low engagement profile of parent in our study; with low prevalence in both studies (14 and 15\%, respectively). The complete influencers reported high use of all practices like the high engagement parents in our study. Finally, O'Connor et al. identified 3 clusters of FPPs related to vegetable and fruit consumption among U.S. parents: indiscriminate food parenting, non-directive food parenting, and low-involved food parenting (similar to our low involvement group in our study) [7]. The nondirective food parenting profile appears similar to the healthy eating environment parents by using enhanced availability and teachable moments' practices, but less firm discipline practices than the other clusters. Taken together, our findings suggest that there are parent profiles who use either multiple FPP simultaneously or only a few practices to influence their children's eating behaviours.

This study found that race/ethnicity could potentially be associated with differences in FPP profiles. However, since non-White parents in this sample constituted a heterogenous groups of parents, interpreting our findings related to potential racial or ethnic differences is limited. Previous research suggests there may be cultural differences in feeding norms and practices as well as economic disparities across racial groups which could contribute to a parent's decision to utilize specific FPP $[19,20,27-32]$. A study conducted in a large population-based sample of U.S. parents of varied and diverse minorities groups suggest that the use of controlling FPP, such as pressuring children to eat and restricting children's intake, is common among racial minority parents [19]. Findings from cross-sectional studies suggests that non-White Hispanics [20, 27] and ChineseAmerican parents [29] are more likely to endorse controlling feeding behaviours such as pressure to eat and restrictive feeding practices compared to White parents. Our findings suggest a more nuanced picture; nonWhite parents in our sample tended to belong to the high engagement, reactive and controlling profiles compared to the healthy environment, high structure and low engagement profiles. This suggest that while some nonWhite parents may use controlling practices, they simultaneously could be using autonomy promoting (reactive parents) as well as autonomy supportive practices (high engagement parents). These findings highlight the need for clinicians to consider the plurality of practices parents may use and the need for culturally competent and safe approaches to encourage health promoting FPPs among parents.

Although some research suggest that fathers employ unique sets of FPP (that set them apart from mothers) $[33,34]$, we found that gender was not a strong predictor of parent profiles. Compared to fathers, mothers were more likely to fall in the healthy eating environment profile compared to low engagement profile. This supports the finding by Davison et al. [34] that while fathers consider themselves responsible for feeding children, their involvement still lags behind or tends to be at a lower level than for mothers. Studies in Canada still consistently demonstrate that women remain responsible for the bulk of house work (despite men's increasing involvement in household-related tasks), including assuming responsibility for the health and well-being of family members $[35,36]$.

Differences in children's eating behaviours were observed among parent profiles, which lend support for the validity and utility of the profiles obtained with the LCA. As expected, parents who used more controlling FPP (high engagement, reactive and controlling parents) also reported higher emotional overeating and food responsiveness (more "food approach" behaviours). This finding is in line with previous research suggesting that parents who perceive their child as wanting to eat for emotional reasons or simply as "having a big appetite" may be more likely to employ more coercive controlling practices (e.g. restricting for weight) in order to shape their child's dietary intakes (despite evidence suggesting these are counterproductive measures and linked with 
excessive weight gain $[37,38])$. At the same time, we found that parents who used simultaneously controlling and autonomy promoting practices (high engagement, reactive parent profiles) also reported the highest satiety responsiveness scores (a more "food avoidant" behaviour). Previous literature suggests that using other controlling practices such as pressuring the child to eat can result in a counterproductive effect of more food avoidant behavior [39], which is reflected in our findings with satiety responsiveness. There is growing consensus of the bidirectional relationship between parental FPP and children's eating behaviours, wherein parents may increase their controlling behaviours as a result of a concern that their child is leaving too much food on their plate $[4,40]$. The finding that parents who used the most favourable combination of FPP (healthy eating environment) also reported the lowest food fussiness scores was not surprising and aligns with previous research indicating that structure and autonomy promoting FPP are associated with more healthful eating behaviours among children [3, 41].

Strengths of this study include a sampling approach to target mothers and fathers, a relatively large and racially diverse sample of Canadian parents, as well as the use of a validated food items bank to measure FPP. There are also important limitations that deserve consideration. This study employed a cross sectional design so no causality can be inferred between FPP profiles and children's eating behaviours. This study assessed FPPs in a sample of elementary school-age children (age 5-12 years) and as such, it is possible that the relationships reported here may not be generalizable to younger children or adolescents. Finally, while the proportion of non-White parents in this sample (49\%) was relatively high (approximately $30 \%$ of total population in Canada is nonWhite [42]), the analysis dichotomized the race variable into two groups (White vs. non-White parents) in order to gain statistical power when exploring racial differences among FPP profiles. In doing so, this analysis could have missed important differences in FPP profiles among non-White parents in this sample (for e.g. differences FPP profiles between East vs. South Asian parents). Future FPP research should consider focusing on visible minority parents in Canada to determine whether the profiles identified here remain relevant and are associated with eating behaviours among children.

\section{Conclusion}

In summary, this study identified 6 profiles of FPPs among Canadian parents. Researchers and practitioners should consider that parents may use simultaneously a wide variety of FPP and therefore adopt a personcentered approach in designing interventions to encourage specific combinations of FPP associated with more healthful dietary behaviours. This study also demonstrates how parent profiles predicted children's eating behaviours, suggesting it may be important for clinicians to provide guidance to parents to establish and maintain structure and autonomy promoting FPPs, both of which were associated with lower food responsiveness and emotional overeating. Future longitudinal research is needed to evaluate the influence of FPP parent profiles on the development of children's eating behaviors, dietary intakes and weight status.

\section{Abbreviations \\ avePP: Average Posterior Probability; AWE: Approximate weight of evidence criterion; BF: Bayes factor; BLRT: Bootstrap likelihood ratio test; BIC: Bayesian information criterion; CAIC: Consistent Akaike Information Criterion; cmP: Correct model probability; FFP: Food parenting practices; LCA: Latent class analysis; SABIC: Sample-size Adjusted Bayesian Information Criterion; VLMR-LRT: Vuong-Lo-Mendell-Rubin Likelihood Ratio Test}

\section{Supplementary Information}

The online version contains supplementary material available at https://doi. org/10.1186/s12966-021-01119-6.

\section{Additional file 1.}

\section{Authors' contributions}

LCM, TMO and SOH designed the study. LCM oversaw the data collection. CTL conceptualized the paper with LCM. ODJG performed the analyses under CTL and LCM supervision. CTL, ODJG, and LCM provided input in the interpretation of the data. CTL drafted the manuscript with help from ODJG and LCM. All authors critically assessed draft of the manuscript. All authors read and approved the final manuscript.

\section{Funding}

This study was funded by the Canadian Institutes of Health Research given to LCM (201109MOP-2585565-PH2-CAAA-143786). LCM received salary support from the BC Children's Hospital Research Institute. CTL received a post-doctoral fellowship from the Canadian Institutes of Health Research. This work is also a publication of the US Department of Agriculture (USDA/ARS Children's Nutrition Research Center, Department of Pediatrics, BMC funded in part by the USDA/ARS (Cooperative agreement 58-3092-5-001 to TMO). The contents of this publication do not necessarily reflect the views or policies of the USDA, nor does mention of organizations imply endorsement from the US government.

\section{Availability of data and materials}

Please contact the corresponding author (LCM at Imasse@bcchr.ubc.ca) for any questions about the study including data requests or study materials.

\section{Declarations}

Ethics approval and consent to participate

The protocol was approved by the Research Ethics Board at the University of British Columbia (H12-00246). Potential participants consented to be part of the web-based panel and consented to be part of the study before they completed the online questionnaire. All participants provided online consents.

Consent for publication

Not applicable.

Competing interests

The authors declare that they have no competing interests. 


\section{Author details}

${ }^{1}$ Department of Family Relations and Applied Nutrition, The University of Guelph, Guelph, ON N1G 1Y1, Canada. ${ }^{2}$ School of Population and Public Health University of British Columbia, BC Children's Hospital Research Institute, F508-4490 Oak Street, Vancouver, BC V5Z 4H4, Canada. ${ }^{3}$ USDA/ARS Children's Nutrition Research Center, Baylor College of Medicine, 1100 Bates St, Houston, TX 77030, USA.

\section{Received: 19 November 2020 Accepted: 3 April 2021} Published online: 04 May 2021

\section{References}

1. Birch L, Savage JS, Ventura A. Influences on the development of Children's eating Behaviours: from infancy to adolescence. Can J Diet Pr Res. 2007;68: s1-56.

2. Birch LL, Fisher JA. Appetite and eating behavior in children. Pediatr Clin N Am. 1995;42(4):931-53. https://doi.org/10.1016/S0031-3955(16)40023-4.

3. Vaughn AE, Ward DS, Fisher JO, Faith MS, Hughes SO, Kremers SPJ, et al. Fundamental constructs in food parenting practices: a content map to guide future research. Nutr Rev. 2016;74(2):98-117. https://doi.org/10.1093/ nutrit/nuv061.

4. Larsen JK, Hermans RCJ, Sleddens EFC, Engels RCME, Fisher JO, Kremers SSPJ. How parental dietary behavior and food parenting practices affect children's dietary behavior. Interacting sources of influence? Appetite. 2015: 89:246-57. https://doi.org/10.1016/j.appet.2015.02.012.

5. Rodgers RF, Paxton SJ, Massey R, Campbell KJ, Wertheim EH, Skouteris $H_{\text {, }}$ et al. Maternal feeding practices predict weight gain and obesogenic eating behaviors in young children: a prospective study. Int J Behav Nutr Phys Act. 2013;10(1):24. https://doi.org/10.1186/1479-5868-10-24.

6. Blissett J, Haycraft E, Farrow C. Inducing preschool children's emotional eating: relations with parental feeding practices. Am J Clin Nutr. 2010;92(2): 359-65. https://doi.org/10.3945/ajcn.2010.29375.

7. O'Connor TM, Hughes SO, Watson KB, Baranowski T, Nicklas TA, Fisher JO, et al. Parenting practices are associated with fruit and vegetable consumption in pre-school children. Pub Health Nutr. 2010;13(1):91-101. https://doi.org/10.1017/\$1368980009005916.

8. Loth KA, Uy M, Neumark-Sztainer D, Fisher JO, Berge JM. A qualitative exploration into momentary impacts on food parenting practices among parents of pre-school aged children. Appetite. 2018;130:35-44. https://doi. org/10.1016/j.appet.2018.07.027.

9. Berge JM, Tate A, Trofholz A, Fertig A, Crow S, Neumark-Sztainer D, et al. Examining within- and across-day relationships between transient and chronic stress and parent food-related parenting practices in a racially/ ethnically diverse and immigrant population. Int J Behav Nutr Phys Act. 2018;15(1):7. https://doi.org/10.1186/s12966-017-0629-1.

10. Loth KA, MacLehose RF, Fulkerson JA, Crow S, Neumark-Sztainer D. Foodrelated parenting practices and adolescent weight status: a populationbased study. Pediatrics. 2013;131(5):e1443-50. https://doi.org/10.1542/peds.2 012-3073.

11. Power TG. Parenting dimensions and styles: A brief history and recommendations for future research. Child Obes. 2013;9:S-14-S-21.

12. Jennings KM, Loth KA, Tate AD, Miner MH, Berge JM. Application of latent profile analysis to define subgroups of parenting styles and food parenting practices. Appetite. 2019;139:8-18. https://doi.org/10.1016/j.a ppet.2019.04.001.

13. Thomson JL, Hennessy E, Landry AS, Goodman MH. Patterns of food parenting practices regarding fruit and vegetables among parentadolescent dyads. Child Obes. 2020;16(5):340-9. https://doi.org/10.1089/chi.2 020.0087 .

14. Mâsse LC, O'Connor TM, Tu AW, Hughes SO, Beauchamp MR, Baranowski T. Conceptualizing physical activity parenting practices using expert informed concept mapping analysis. BMC Public Health. 2017;17:1-11.

15. Masse L, O'Connor T, Lin Y, Hughes S, Tugault-Lafleur C, Baranowski T, Beauchamp M. Calibration of the Food Parenting Practice Item Bank: Tools for improving the measurement of food parenting practices of 5-12 year old children. Int J Behav Nutr Phys Act. 2020;17(140). https://doi.org/10.11 86/s12966-020-01049-9.

16. Wardle J, Guthrie CA, Sanderson S, Rapoport L. Development of the children's eating behaviour questionnaire. J Child Psychol Psychiatry. 2001; 42(7):963-70. https://doi.org/10.1111/1469-7610.00792.
17. van der Horst K, Sleddens EFC. Parenting styles, feeding styles and foodrelated parenting practices in relation to toddlers' eating styles: a clusteranalytic approach. Plos One. 2017;12(5):e0178149. https://doi.org/10.1371/ journal.pone.0178149.

18. French SA, Epstein LH, Jeffery RW, Blundell JE, Wardle J. Eating behavior dimensions. Associations with energy intake and body weight. A review. Appetite. 2012;59(2):541-9.

19. Loth KA, MacLehose RF, Fulkerson JA, Crow S, Neumark-Sztainer D. Eat this, not that! Parental demographic correlates of food-related parenting practices. Appetite. 2013;60(1):140-7. https://doi.org/10.1016/j.appet.2012.09. 019.

20. Worobey J, Borrelli A, Espinosa C, Worobey HS. Feeding practices of mothers from varied income and racial/ethnic groups. Early Child Dev Care. 2013;183(11):1661-8. https://doi.org/10.1080/03004430.2012.752735.

21. Hagenaaars J, McCutcheon A. Applied latent class analysis. New York: Cambridge University Press; 2002. https://doi.org/10.1017/CBO97805114 99531.

22. Nylund-Gibson K, Choi AY. Ten frequently asked questions about latent class analysis. Transl Issues Psychol Sci. 2018;4(4):440-61. https://doi.org/10.1 037/tps0000176

23. Bray BC, Lanza ST, Tan X. Eliminating Bias in classify-analyze approaches for latent class analysis. Struct Equ Model. 2015;22(1):1-11. https://doi.org/10.1 080/10705511.2014.935265.

24. Zaltz DA, Pate RR, O'Neill JR, Neelon B, Benjamin-Neelon SE. Barriers and facilitators to compliance with a state healthy eating policy in early care and education centers. Child Obes. 2018;14(6):349-57. https://doi.org/10.1 089/chi.2018.0077.

25. Muthén LK, Muthén BO. MPlus (version 8.4). Los Angeles: Muthén \& Muthén; 2019.

26. StataCorp. Stata Statistical Software. College Station: StataCorp LLC; 2019.

27. Cardel M, Willig AL, Dulin-Keita A, Casazza K, Mark Beasley T, Fernández JR Parental feeding practices and socioeconomic status are associated with child adiposity in a multi-ethnic sample of children. Appetite. 2012;58(1): 347-53. https://doi.org/10.1016/j.appet.2011.11.005.

28. Blissett J, Bennett C. Cultural differences in parental feeding practices and children's eating behaviours and their relationships with child BMI: a comparison of black afro-Caribbean, white British and white German samples. Eur J Clin Nutr. 2013;67(2):180-4. https://doi.org/10.1038/ejcn.2 012.198.

29. Huang SH, Parks EP, Kumanyika SK, Grier SA, Shults J, Stallings VA, et al. Child-feeding practices among Chinese-American and non-Hispanic white caregivers. Appetite. 2012;58(3):922-7. https://doi.org/10.1016/j.appet.2012. 02.008 .

30. Pai HL, Contento I. Parental perceptions, feeding practices, feeding styles, and level of acculturation of Chinese Americans in relation to their schoolage child's weight status. Appetite. 2014;80:174-82. https://doi.org/10.1016/ j.appet.2014.04.029.

31. Evans A, Seth JG, Smith S, Harris KK, Loyo J, Spaulding C, et al. Parental feeding practices and concerns related to child underweight, picky eating, and using food to calm differ according to ethnicity/race, acculturation, and income. Matern Child Health J. 2011;15(7):899-909. https://doi.org/10.1007/ s10995-009-0526-6.

32. Bauer KW, MacLehose R, Loth KA, Fisher JO, Larson NI, Neumark-Sztainer D. Eating- and weight-related parenting of adolescents in the context of food insecurity. J Acad Nutr Diet. 2015;115(9):1408-16. https://doi.org/10.1016/j.ja nd.2015.01.011.

33. Khandpur N, Blaine RE, Fisher JO, Davison KK. Fathers' child feeding practices: a review of the evidence. Appetite. 2014;78:110-21. https://doi. org/10.1016/j.appet.2014.03.015.

34. Davison KK, Haines J, Garcia EA, Douglas S, McBride B. Fathers' food parenting: A scoping review of the literature from 1990 to 2019. Pediatr Obes. 2020;15:e12654. https://doi.org/10.1111/ijpo.12654.

35. Moyser M, Burlock A. Time use: Total work burden, unpaid work, and leisure 2018. Available from: https://www150.statcan.gc.ca/n1/pub/89-503-x/201 5001/article/54931-eng.htm

36. McCormack K. Stratified reproduction and poor women's resistance. Gend Soc. 2005;19(5):660-79. https://doi.org/10.1177/0891243205278010.

37. Tschann JM, Martinez SM, Penilla C, Gregorich SE, Pasch LA, de Groat CL, et al. Parental feeding practices and child weight status in Mexican American families: a longitudinal analysis. Int J Behav Nutr Phys Act. 2015;12: $1-10$. 
38. Hughes SO, Power TG, O'connor TM, Orlet Fisher J, Chen TA. Maternal feeding styles and food parenting practices as predictors of longitudinal changes in weight status in Hispanic preschoolers from low-income families. J Obes. 2016:(7201082).

39. Jansen PW, Roza SJ, Jaddoe WW, Mackenbach JD, Raat H, Hofman A, et al. Children's eating behavior, feeding practices of parents and weight problems in early childhood: results from the population-based generation R study. Int J Behav Nutr Phys Act. 2012;9:1-11.

40. Jansen E, Williams KE, Mallan KM, Nicholson JM, Daniels LA. Bidirectional associations between mothers' feeding practices and child eating behaviours. Int J Behav Nutr Phys Act. 2018;15(1):3. https://doi.org/10.1186/ s12966-018-0644-x.

41. Yee AZH, Lwin MO, Ho SS. The influence of parental practices on child promotive and preventive food consumption behaviors: a systematic review and meta-analysis. Int J Behav Nutr Phys Act. 2017;14(1):47. https://doi.org/1 0.1186/s12966-017-0501-3.

42. Statistics Canada. Immigration and Ethnocultural Diversity in Canada. Ottawa: Statistics Canada; 2011. Retrieved from https://www12.statcan.gc.ca/ nhs-enm/2011/as-sa/99-010-x/99-010-x2011001-eng.pdf.

\section{Publisher's Note}

Springer Nature remains neutral with regard to jurisdictional claims in published maps and institutional affiliations.

Ready to submit your research? Choose BMC and benefit from:

- fast, convenient online submission

- thorough peer review by experienced researchers in your field

- rapid publication on acceptance

- support for research data, including large and complex data types

- gold Open Access which fosters wider collaboration and increased citations

- maximum visibility for your research: over $100 \mathrm{M}$ website views per year

At BMC, research is always in progress.

Learn more biomedcentral.com/submissions 